\title{
Efficacy of ketogenic diet on body composition during resistance training in trained men: a randomized controlled trial
}

Salvador Vargas ${ }^{1,2^{*}}$, Ramón Romance ${ }^{2}$, Jorge L. Petro ${ }^{3}$, Diego A. Bonilla ${ }^{3,4}$, Ismael Galancho ${ }^{5}$, Sergio Espinar ${ }^{5}$, Richard B. Kreider ${ }^{6}$ and Javier Benítez-Porres ${ }^{2}$

\begin{abstract}
Background: Ketogenic diets (KD) have become a popular method of promoting weight loss. More recently, some have recommended that athletes adhere to ketogenic diets in order to optimize changes in body composition during training. This study evaluated the efficacy of an 8-week ketogenic diet (KD) during energy surplus and resistance training (RT) protocol on body composition in trained men.

Methods: Twenty-four healthy men (age $30 \pm 4.7$ years; weight $76.7 \pm 8.2 \mathrm{~kg}$; height $174.3 \pm 19.7 \mathrm{~cm}$ ) performed an 8-week RT program. Participants were randomly assigned to a KD group $(n=9)$, non-KD group $(n=10, \mathrm{NKD})$, and control group $(n=5, C G)$ in hyperenergetic condition. Body composition changes were measured by dual energy X-ray absorptiometry (DXA). Compliance with the ketosis state was monitored by measuring urinary ketones weekly. Data were analyzed using a univariate, multivariate and repeated measures general linear model (GLM) statistics.

Results: There was a significant reduction in fat mass (mean change, $95 \% \mathrm{Cl}$; $p$-value; Cohen's d effect size [ES]; $0.8[-1.6,-0.1] \mathrm{kg} ; p<0.05 ; \mathrm{ES}=-0.46)$ and visceral adipose tissue $(-96.5[-159.0,-34.0] \mathrm{g} ; p<0.05 ; \mathrm{ES}=-0.84)$, while no significant changes were observed in the NKD and CG in fat mass $(-0,5[-1.2,0.3] \mathrm{kg} ; p>0.05 ; E S=-0.17$ and $-0,5[-2.4,1.3] \mathrm{kg} ; p>0.05 ; \mathrm{ES}=-0.12$, respectively) or visceral adipose tissue $(-33.8[-90.4,22.8] ; p>0.5 ; \mathrm{ES}=$ -0.17 and $1.7[-133.3,136.7] ; p>0.05 ; E S=0.01$, respectively). No significant increases were observed in total body weight $(-0.9[-2.3,0.6] ; p>0.05 ; \mathrm{ES}=[-0.18])$ and muscle mass $(-0.1[-1.1,1.0] ; p>0,05 ; \mathrm{ES}=-0.04)$ in the $\mathrm{KD}$ group, but the NKD group showed increases in these parameters $(0.9[0.3,1.5] \mathrm{kg} ; p<0.05 ; \mathrm{ES}=0.18$ and $(1.3[0.5$, 2.2] kg; $p<0,05 ; E S=0.31$, respectively). There were no changes neither in total body weight nor lean body mass $(0.3[-1.2,1.9] ; p>0.05 ; \mathrm{ES}=0.05$ and $0.8[-0.4,2.1] ; p>0.05 ; \mathrm{ES}=0.26$, respectively) in the CG.
\end{abstract}

Conclusion: Our results suggest that a KD might be an alternative dietary approach to decrease fat mass and visceral adipose tissue without decreasing lean body mass; however, it might not be useful to increase muscle mass during positive energy balance in men undergoing RT for 8 weeks.

Keywords: Hypertrophy, Ketosis, High-fat diet, Fat distribution, Bodybuilding

\footnotetext{
* Correspondence: salvadorvargasmolina@gmail.com

${ }^{1}$ EADE-University of Wales Trinity Saint David, Málaga, Spain

${ }^{2}$ Human Kinetics and Body Composition Laboratory, Faculty of Education

Sciences, University of Málaga, Málaga, Spain

Full list of author information is available at the end of the article
}

(C) The Author(s). 2018 Open Access This article is distributed under the terms of the Creative Commons Attribution 4.0 International License (http://creativecommons.org/licenses/by/4.0/), which permits unrestricted use, distribution, and reproduction in any medium, provided you give appropriate credit to the original author(s) and the source, provide a link to the Creative Commons license, and indicate if changes were made. The Creative Commons Public Domain Dedication waiver (http://creativecommons.org/publicdomain/zero/1.0/) applies to the data made available in this article, unless otherwise stated. 


\section{Background}

Macronutrient manipulation has become a key nutrition component that, implemented in synergy with training, seeks to improve physical appearance, performance and human health. Among many dietary strategies that have been adopted, ketogenic diet (KD) is a subtype of lowcarbohydrate and high-fat diet that needs to be planned considering special dietary features (such as the proportion of macronutrients) and physiological changes (ketosis generation). In view of the foregoing, KD should be planned from an objective perspective, checking for any increase in circulating ketone bodies (KB), a distinctive marker of physiological/nutritional ketosis. Main KB (acetate, acetone, and $\beta$-hydroxybutyrate) are produced in the liver under low-carbohydrate availability conditions, acting as an alternative energy source for peripheral tissue, such as skeletal muscle, brain and heart [1]. To achieve a state of ketosis through a KD, carbohydrate intake should be reduced to a maximum of around $50 \mathrm{~g}$ per day, or $10 \%$ of total caloric intake during the day, while protein intake is moderate or high (e.g. $\approx 1.2$ to $1.5 \mathrm{~g} \cdot \mathrm{kg}^{-1} \cdot \mathrm{d}^{-1}$ ). Remaining energy intake is predominantly from fats $(\approx 60$ to $80 \%$ ), depending on the degree of displacement of carbohydrates and proteins [2].

Under normal conditions (with no KD diet or long fasting periods), the circulating $\mathrm{KB}$ values ( $\beta$-hydroxybutyrate being the primary $\mathrm{KB})$ are very low $\left(<3 \mathrm{mmol} \cdot \mathrm{L}^{-}\right.$ 1 ); however, during physiological ketosis, as a result of the $\mathrm{KD}$, ketonemia can reach maximum levels of $\approx 7-$ $8 \mathrm{mmol} \cdot \mathrm{L}^{-1}$ with no significant changes in blood $\mathrm{pH}$ [3]. At this point, it is important to clarify the difference between physiological ketosis and diabetic ketoacidosis, where the concentration of $\mathrm{KB}$ in the blood can exceed $\approx 20 \mathrm{mmol} \cdot \mathrm{L}^{-1}$, with a significant reduction in blood $\mathrm{pH}$. In healthy population, the circulating $\mathrm{KB}$ values do not exceed $\approx 8 \mathrm{mmol} \cdot \mathrm{L}^{-1}$, because the central nervous system uses these molecules efficiently as a source of energy, instead of glucose [4].

Several studies have focused on the effects of KDs on reducing body mass $[5,6]$, on improving health conditions, or as part of managing certain pathologies such as type 2 diabetes mellitus [7, 8], nervous system disorders such as epilepsy [9-11], and in different types/stages of cancer [12-16]. Currently, there is some controversy surrounding the advantages or disadvantages of KD for sports performance. It has been argued, on the one hand, that there are beneficial effects associated with the reduction of total body mass and body fat, a higher rate of fat oxidation, lower glucose oxidation and a reduction in the rate of muscle glycogen utilization during physical exertion, which represents an advantage in resistance exercise [17]. On the other hand, physiological mechanisms have been cited that may limit performance in resistance training due to central fatigue, possibly because of increased circulation of non-esterified fatty acids which increases competition between these and tryptophan for albumin, resulting in an increase in free tryptophan, which in turn causes a greater absorption by the brain and subsequent augmentation of 5-hydroxytryptamine (serotonin) synthesis, a neurotransmitter linked to the feeling of lethargy and tiredness that may contribute to nerve signal losses at central level and a decrease in motivation. In addition, greater oxidation of amino acids can occur, which increases the concentration of ammonia, contributing to central fatigue [17]. In general, several authors have also established that low-carbohydrate diets or KD do not seem to be superior or offer advantages for resistance exercise, compared with carbohydrate-rich diets $[18,19]$.

With regards to the effects of KD combined with resistance training (RT), such as muscle hypertrophy, there is even less information available, when compared with studies conducted on endurance-type performance. Even though KD can provide adequate quantities of proteins and calories necessary for muscle-protein synthesis induced by RT, they induce a state similar to fasting, prompting alterations in the metabolic pathways and molecular processes relating to autophagy and stress resistance [20], which consequently might hinder the building of muscle mass.

Considering the need to study on the effects of KD in resistance-trained subjects, the purpose of this study was to determine if following a KD hypercaloric diet would promote greater gains in fat free mass and fat loss during a hypertrophic training period in resistance-trained men. We hypothesized that a KD with caloric surplus in combination with RT in trained men would have a positive impact in fat reduction, and it would benefit the gains in lean body mass (LBM).

\section{Methods \\ Study design}

This study was conducted as a randomized, parallel arm, controlled, prospective study. The independent variable was nutritional intervention. The primary outcome variables were changes in body composition.

\section{Participants}

Figure 1 presents a CONSORT diagram. Twenty-four healthy men with more than 2 years of continuous experience in overload training participated in this randomized controlled study (age $=30 \pm 4.5$ years; height $=177 \pm 3.4 \mathrm{~cm}$; weight $=76.7 \pm 5.7 \mathrm{~kg} ; \mathrm{BMI}=23.4$ $\pm 2.2 \mathrm{~kg} / \mathrm{m}^{2}$ ). All volunteered their participation and agreed to complete the supervised training and diet protocols during the 8 weeks of the study. Subjects who had consumed androgenic-anabolic steroids during the last 2 years or those who consumed any type of dietary supplement during the study were excluded. The subjects were 


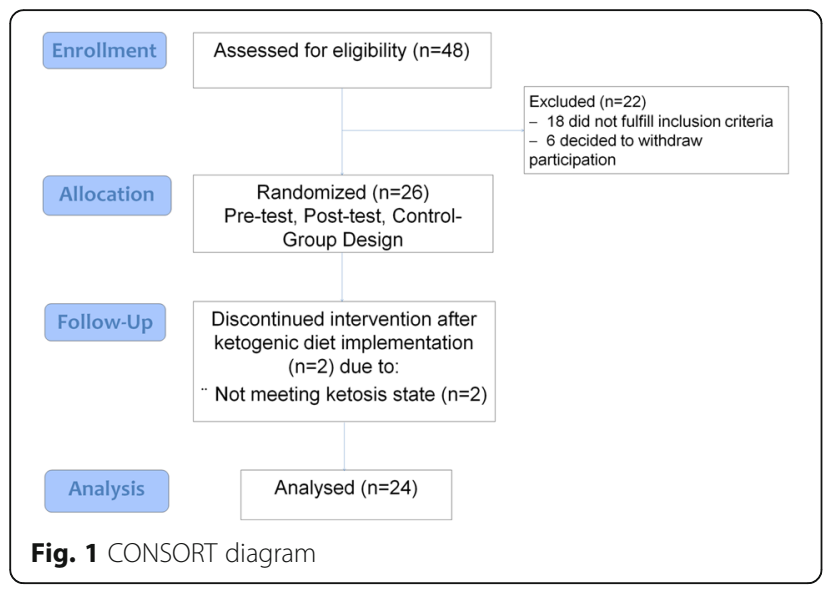

advised of the potential risks of the experiment and signed an informed consent form. The study was developed following the ethical guidelines of the Declaration of Helsinki [21]. The investigation was developed in Málaga (Spain). The first evaluation took place on February 2017 and the second measurement on April of the same year.

\section{Procedures \\ Body composition}

Total and regional body composition were estimated using a Hologic QDR 4500 dual-energy x-ray absorptiometry (DXA) scanner (Hologic Inc., Bedford, MA, $U S A)$. Each subject was scanned by a certified technician, and the distinguished bone and soft tissue, edge detection, and regional demarcations were done by computer algorithms with APEX Software 3.0 (APEX Corporation Software, Pittsburg, PA, USA). For each scan, subjects wore sport clothes and were asked to remove all materials that could attenuate the X-ray beam, including jewelry items. Calibration of the densitometer was checked daily against standard calibration block supplied by the manufacturer.

Abdominal region was delineated by an upper horizontal border located at half of the distance between acromions and external end of iliac crests, a lower border determined by the external end of iliac crests, and the lateral borders extending to the edge of the abdominal soft tissue. All trunk tissue within this standardized height region was selected for analysis. To determine intertester reliability, two different observers selected the area for each subject manually.

\section{Nutrition intervention}

The participants were randomly assigned to a KD group $(n=9)$, non-KD (NKD) $(n=10)$ group, and control group (CG) $(n=5)$. Compliance with the ketosis state was monitored by measuring urinary ketones weekly using reagent strips (Ketostix, Bayer Vital GmbH, Leverkusen, Germany), from week two to the end of the study in KD group. Under the supervision of a registered dietitian, the subjects were given a detailed questionnaire about their work and sociocultural activities, as well as dietary preferences in order to estimate the basal metabolic rate and physical activity-related energy expenditure. Subjects were classified as active in their day-to-day lives, estimating total energy expenditure in line with the indications [22]. Once energy expenditure was determined, together with their weekly training load, a moderate energy surplus was established for experimental groups, since it has been noted that trained men do not require energy increases as high as novice subjects $[23,24]$. To guarantee a hyperenergetic condition, a daily energy intake of $\approx 39 \mathrm{kcal} \cdot \mathrm{kg}^{-1} \cdot \mathrm{d}^{-1}$ was used in all subjects. To ensure a maximal anabolic response, NKD group was given a protein intake of 2 $\mathrm{g} \cdot \mathrm{kg}^{-1} \cdot \mathrm{d}^{-1}$, as it is recommended for building muscle mass in trained subjects $[2,22,25]$, while $25 \%$ of total energy intake corresponded to fat and the remaining calories were given in carbohydrates. Macronutrient distribution for NKD group was about 55\% $\mathrm{CHO} ; 20 \% \mathrm{PRO}$ and 25\% FAT. On the other hand, $\approx 42 \mathrm{~g}$ total carbohydrates per day were administered to $\mathrm{KD}$ group to ensure the ketosis state [26, 27]. Protein intake was $2 \mathrm{~g} \cdot \mathrm{kg}^{-1} \cdot \mathrm{d}^{-1}$, and the remaining calories were given in fat with a estimating of $3.2 \mathrm{~g} \cdot \mathrm{kg}^{-1} \cdot \mathrm{d}^{-1}$. Macronutrient distribution for KD group was about $<10 \% \mathrm{CHO} ; 20 \%$ $\mathrm{PRO}$ and $70 \%$ FAT. Ad libitum meal timing and frequency throughout the day was allowed to improve dietary adherence. Even though a specific number of meals per day is not necessary, provided the daily energy intake is guaranteed [22], from 3 to 6 meals were recommended, with the respective foods selected for the KD group.

\section{Training protocol}

During 8 weeks both KD and NKD groups completed four sessions per week of a hypertrophy training protocol, organized into a 2-days upper- and 2-days lower-limb, with $72 \mathrm{~h}$ of rest between sessions to encourage recovery [28] (Fig. 2).

Participants were experienced in overload training and used to different nutritional strategies; therefore, no familiarization session was necessary. Moderate to high loads were used to encourage mechanical tension [29]. Rest between sets lasted $3 \mathrm{~min}$, so that volume did not decline [30, 31]. Cadences were explosive in the concentric activation, and $3 \mathrm{~s}$ long during the eccentric contraction to generate more muscle damage [29, 32]. Two weekly stimuli were provided for each muscle group in order to optimize the final results [33]. Push and pull exercises were interspersed for better recovery [34]. Subjects from both groups were asked to increase loads as long as they exceeded repetition rates and had no error technique. During the intervention, all participants were 


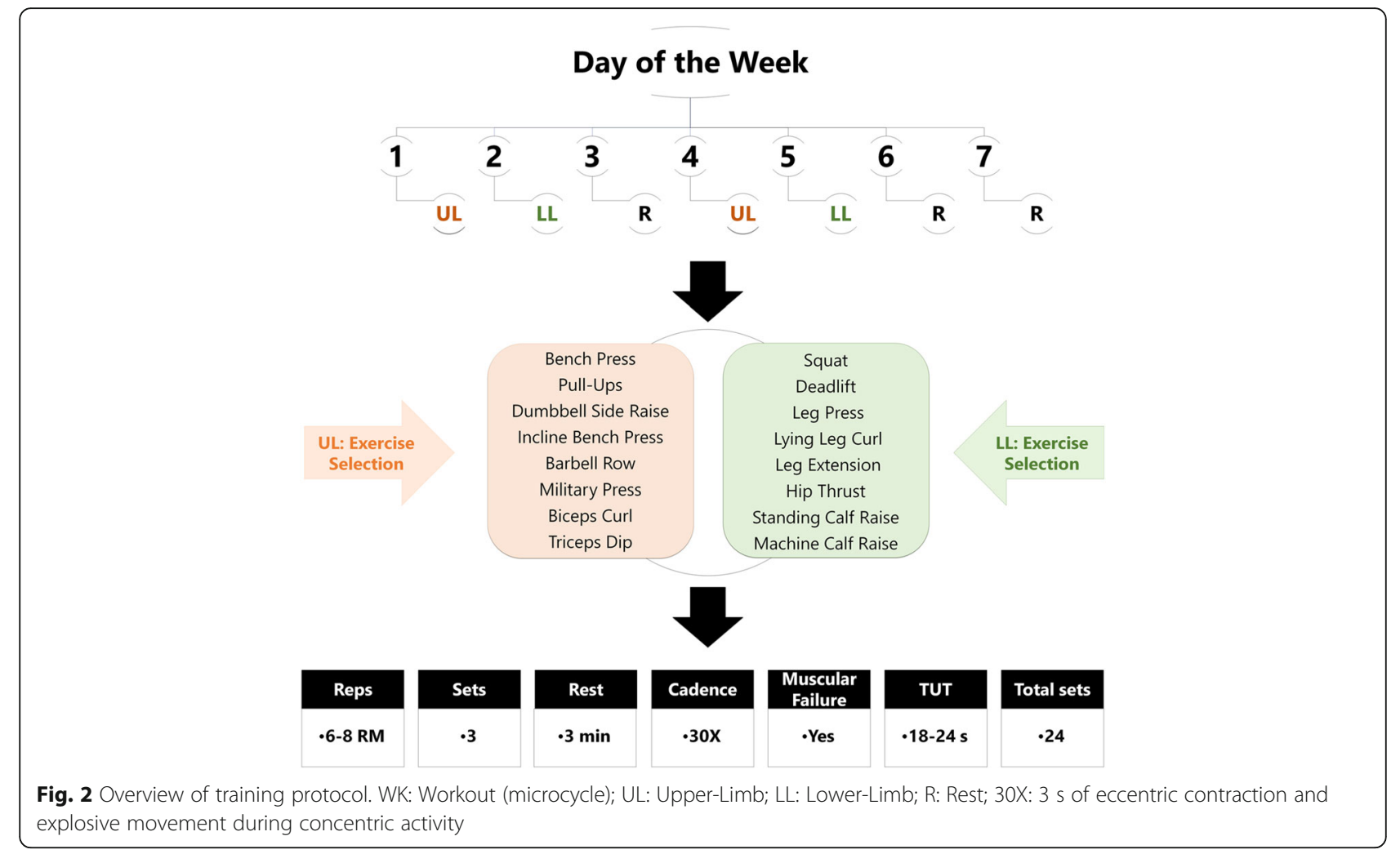

monitored by an RT specialist who supervised and checked the load at each training session, and made the relevant adjustments when was necessary. Meanwhile, men in control group were asked to maintain their current level of physical activity during the study.

\section{Statistical analysis}

Descriptive statistics tests were applied (mean and standard deviation, SD). Data were analyzed using a univariate, multivariate and repeated measures general linear model (GLM), with two levels by time (pre- and post-test) and considering groups (KD, NKD and CG) as inter-subjects factor. Wilks' Lambda multivariate tests are reported to describe overall effects of related variables analyzed. Greenhouse-Geisser univariate tests with least significant difference and post-hoc comparisons (Bonferroni correction) are presented for individual variables analyzed. Partial eta squared effect sizes $\left(\eta p^{2}\right)$ were also reported on select variables as an indicator of effect size (ES) of the repeated measures GLM. An Eta squared around 0.02 was considered small, 0.13 medium, and 0.26 large [35]. Furthermore, one-way analysis of variance (ANOVA), with a 95.0\% confidence level and Bonferroni post-hoc correction, as is recommended for these studies [36, 37], was performed to detect between-group differences in the $\Delta$ changes (post-test pre-test). In addition, ES calculation was done with Cohen's $d$, as a standardized measurement based on SD differences; while $\mathrm{d}=0.2$ was considered a small effect, $d=0.5$ was a medium effect and $d=0.8$ was a large effect, which is used as a guide for substantive significance. The normal Gaussian distribution of the data was verified by the Shapiro-Wilk test. Mean changes with 95\% CI's completely above or below baseline are considered significant changes from baseline. These statistical analyses were performed with licensed Statistical Package for the Social Sciences (SPSS) software (SPSS 24.0, SPSS Inc., Chicago, USA) and GraphPad software (GraphPad Prism 7.03, California, USA).

\section{Results}

\section{Baseline characteristics}

A total number of 26 individuals met initial screening criteria and consented to participate in the study (Fig. 1). Two participants did not enter into ketosis state and were excluded from the study, which left nine men for analysis in KD group. Statistical analyses were performed on 24 individuals. Descriptive statistics with baseline characteristics are summarized, by groups in Table 1 .

\section{Body composition}

The statistical results before and after the intervention for total body weight (BW) and body composition; fat mass (FM), visceral adipose tissue (VAT), and LBM are shown in Table 2. Multivariate analysis showed significant overall Wilks' Lambda in time interaction $(p=$ 
Table 1 Characteristics of participants at baseline

\begin{tabular}{lllll}
\hline & CG & KD & NKD & $p$-value \\
\hline Age (years) & $31.6 \pm 4.6$ & $27.6 \pm 4.2$ & $27.1 \pm 5.6$ & 0.276 \\
Height $(\mathrm{cm})$ & $179.9 \pm 7.8$ & $178.3 \pm 4.0$ & $178.3 \pm 6.2$ & 0.873 \\
BW $(\mathrm{kg})$ & $78.9 \pm 6.5$ & $78.8 \pm 7.8$ & $74.6 \pm 5.3$ & 0.306 \\
BMI $\left(\mathrm{kg} \cdot \mathrm{m}^{2}\right)$ & $24.5 \pm 1.7$ & $24.4 \pm 2.6$ & $23.9 \pm 1.6$ & 0.793 \\
FM $(\mathrm{kg})$ & $13.4 \pm 4.5$ & $12.0 \pm 2.7$ & $11.3 \pm 2.6$ & 0.499 \\
LBM $(\mathrm{kg})$ & $65.6 \pm 2.6$ & $66.8 \pm 6.8$ & $63.2 \pm 4.4$ & 0.350 \\
VAT (g) & $757.7 \pm 265.3$ & $688.9 \pm 125.4$ & $658.0 \pm 200.5$ & 0.650
\end{tabular}

Data are means \pm SD; $p<0.05$ is considered significant; $B W$ Total body weight, $B M I$ Body Mass Index, FM Fat mass, LBM Lean body mass, VAT Visceral adipose tissue

0.031; with a large effect size, $\left.\eta \mathrm{p}^{2}=0.36\right)$ and in time $\mathrm{x}$ group $\left(p<0.05\right.$; with a large effect size, $\left.\eta p^{2}=0.264\right)$. On the other hand, univariate analysis revealed significant differences in time $\mathrm{x}$ group interaction between $\mathrm{BW}$, and LBM $(p<0.05)$, with a large effect size for BW $\left(\eta p^{2}>\right.$ 0.36 ); however, no significant differences were found in VAT. Significant differences were observed over time in VAT and LBM, with medium effect size for both $\left(\eta \mathrm{p}^{2}=\right.$ 0.20 and 0.23 , respectively). No significant differences were found after group interaction analysis of the study variables.

According to the results by group, BW increased in KD group $(p<0.05)$, but to a small size $(E S=0.18)$, with no significant differences in the other groups (NKD and CG). With regards to FM, only KD group showed a significant reduction $(p<0.05)$, expressing a medium effect $(E S=-0.46)$. Similarly, VAT only decreased markedly in the KD group $(p<0.05)$, showing a considered large effect $(E S=-0.84)$. Conversely, LBM showed a highly significant increase $(p<0.05)$ with moderate effect $(\mathrm{ES}=$
0.31) in the NKD group; however, although LBM decreased in the KD group, this did not represent a statistically significant difference or significant effect $(p>0.05$; $\mathrm{ES}=-0.04)$.

These results suggest that KD group achieved a positive change in body composition, due to a decrease in BW $(-0.9[-2.3,0.6] \mathrm{kg} ; p>0.05)$ with a reduction in FM $(-0.8[-1.6,-0.1] \mathrm{kg} ; p<0.05)$ and accompanied by a notably lower VAT $(-96.5[-159.0,-34.0] \mathrm{g} ; p<0.05)$. Regarding to LBM, an adequate carbohydrate intake (non-ketogenic or conventional dietary approach), in conjunction with a caloric surplus and a higher protein intake, might be the most viable option for inducing muscle hypertrophy after RT. This last was shown in this study, where there was an increase in $\operatorname{LBM}(1.3[0.5,2.2]$ $\mathrm{kg} ; p<0.05)$ in the NKD group, leading to an increase in BW $(-0.9[-2.3,0.6] \mathrm{kg} ; p<0.05)$. Figure 3 shows significant differences in BW and LBM for NKD group; and FM and VAT for KD group. Likewise, post-hoc analysis showed significant difference in the BW and LBM between KD and NDK groups.

\section{Discussion}

The aim of this study was to determine the efficacy of the KD when combined with an RT program on body composition in trained subjects over a period of 8 weeks of intervention.

We originally hypothesized that this intervention would improve body composition due to a greater reduction in FM and VAT, and an increase in LBM. Our hypothesis is supported by some lines of evidence, but there are contradictory findings due to a lack of studies analyzing the effects of the KD (with and without RT protocol) on FM, VAT and muscle hypertrophy. Human

Table 2 Results before and after the intervention for body composition by groups

\begin{tabular}{|c|c|c|c|c|c|c|}
\hline & & $\begin{array}{l}\text { Pre } \\
(\text { Mean } \pm S D)\end{array}$ & $\begin{array}{l}\text { Post } \\
\text { (Mean } \pm S D)\end{array}$ & ES & Interaction & $p$-value $\left(n p^{2}\right)$ \\
\hline \multirow[t]{3}{*}{ BW } & CG & $78.9 \pm 6.5$ & $79.2 \pm 6.6$ & 0.05 & Time & $0.830(0.002)$ \\
\hline & $\mathrm{KD}$ & $78.8 \pm 7.8$ & $77.4 \pm 7.9$ & -0.18 & Group & $0.437(0.076)$ \\
\hline & NDK & $74.6 \pm 5.3$ & $75.5 \pm 4.9^{*}$ & 0.18 & Time x Group & $0.016(0.327)$ \\
\hline \multirow[t]{3}{*}{ FM } & CG & $13.4 \pm 4.5$ & $12.8 \pm 4.0$ & -0.12 & Time & $0.013(0.258)$ \\
\hline & $\mathrm{KD}$ & $12.0 \pm 2.7$ & $10.9 \pm 2.2^{*}$ & -0.46 & Group & $0.457(0.072)$ \\
\hline & NDK & $11.3 \pm 2.6$ & $10.9 \pm 2.7$ & -0.17 & Time x Group & $0.447(0.074)$ \\
\hline \multirow[t]{3}{*}{ VAT } & $C G$ & $757.7 \pm 265.3$ & $759.4 \pm 317.2$ & 0.01 & Time & $0.031(0.203)$ \\
\hline & $\mathrm{KD}$ & $688.9 \pm 125.4$ & $592.4 \pm 103.1^{*}$ & -0.84 & Group & $0.490(0.066)$ \\
\hline & NDK & $658.0 \pm 200.5$ & $624.2 \pm 201.5$ & -0.17 & Time x Group & $0.130(0.177)$ \\
\hline \multirow[t]{3}{*}{ LBM } & $C G$ & $65.6 \pm 2.6$ & $66.4 \pm 3.5$ & 0.26 & Time & $0.023(0.224)$ \\
\hline & $\mathrm{KD}$ & $66.8 \pm 6.8$ & $66.5 \pm 6.9$ & -0.04 & Group & $0.516(0.061)$ \\
\hline & NDK & $63.2 \pm 4.4$ & $64.6 \pm 4.2^{*}$ & 0.31 & Time $x$ Group & $0.025(0.297)$ \\
\hline
\end{tabular}

Data are means \pm SD; Greenhouse-Geisser univariate $p$-levels are presented for each variable; $p<0.05$ is considered significant; $\left({ }^{*}\right)$ denotes a significant difference from baseline; ES Effect Size (Cohen's d), BW Total body weight, FM Fat mass, VAT Visceral adipose tissue, LBM lean body mass 


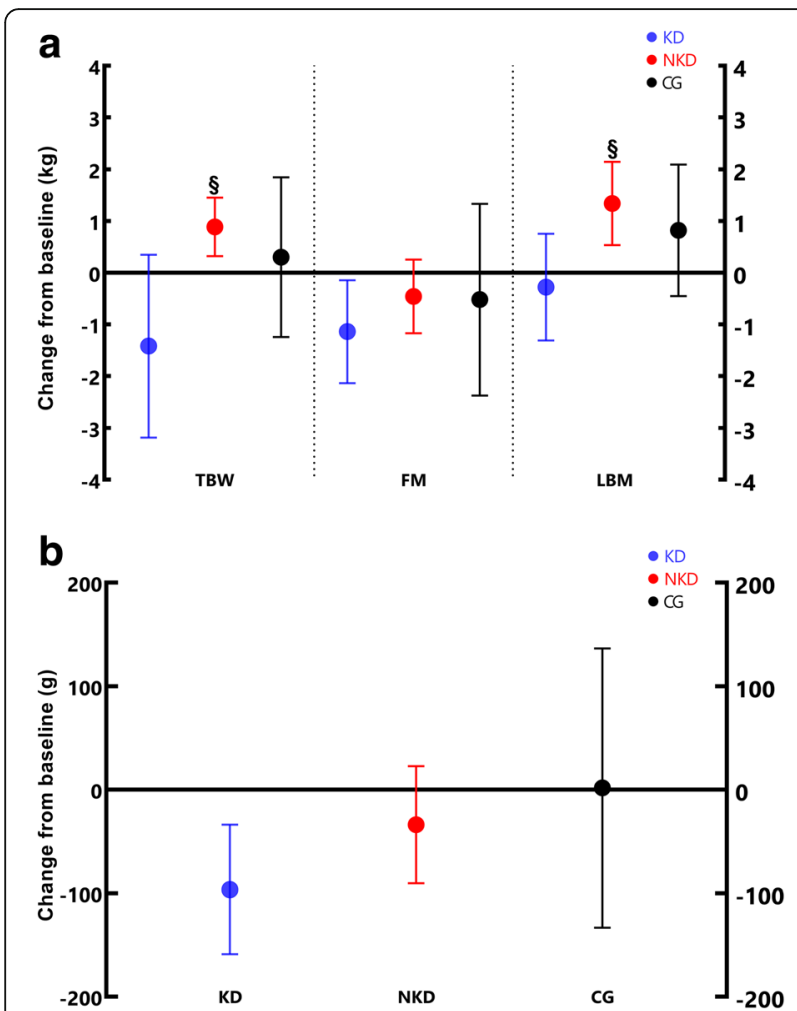

Fig. 3 Changes in body mass and body composition. Mean changes with 95\% Cl's completely above or below the baseline are significant changes; BW: Total body weight; FM: Fat mass; VAT: Visceral adipose tissue; LBM: lean body mass. a Changes in BW, FM, LBM. $\mathbf{b}$ Changes in VAT. \# Significant difference with KD after post-hoc analysis $(p<0.05)$

studies have reported a reduction in FM during and after $\mathrm{KD}$, but with a concomitant loss of of LBM [38-44]. For example, Gomez-Arbelaez [45], found that a low-calorie KD (starting in the initial phases with $\approx 600-800 \mathrm{kcal}$ per day and following the $\mathrm{PNK}^{\circ}$ method) resulted in a decrease in VAT, according to a follow-up study performed over 4 months. Notwithstanding, it should be noted that these studies included obese subjects, in some cases with at least one cardiovascular risk factor and, with no physical exercise intervention, strength training in particular. In another study [46], there was a reduction in adipose mass tissue and a parallel increase in LBM after performing a variety of strength or resistance exercises in moderately active subjects with normal weight; these changes in body composition (especially FM reduction) were attributed in part to a decrease in insulin concentrations. It is probable that the incorporation of RT, together with moderate/high protein consumption and a caloric surplus, may be an important strategy for maintaining fat free mass during KD. In particular, RT alone, or combined with endurance training, accompanied by a hypoenergetic KD, might be useful for the preservation of fat free mass and the increased metabolic rate in obese subjects, as an intervention that deserves further research, considering the complexity of this multifactorial illness [47]. In fact, even though endurance exercise is more effective than RT in reducing VAT [48], a combination of endurance training and RT is more plausible for improving body composition in this population [49]. Since few studies have evaluated the combined effect of the KD and RT in trained subjects on VAT, our study contributes to current literature by showing a significant reduction in VAT after 8 weeks of KD in hyperenergetic condition in resistance-trained men. These results suggest that KD group achieved a positive change in body composition, due to a decrease in BW $(-0.9[-2.3,0.6]$ $\mathrm{kg} ; p>0.05)$ with a reduction in FM $(-0.8[-1.6,-0.1]$ kg; $p<0.05)$ and accompanied by a notably lower VAT $(-96.5[-159.0,-34.0] \mathrm{g} ; p<0.05)$. This supports the need for in-depth analysis about the importance of macronutrient distribution, comparing isoenergetic nutritional programs, on the distribution of body fat.

On the other hand, animal studies on ketosis-induced interventions after KD have not found neither acute nor chronic changes in hypertrophic response in skeletal muscle, when strength exercises were performed, in comparison with a mixed diet of macronutrients [50]; however, a reduction in FM was observed in these rodents [51]. Although these results were obtained in animal models, it seems that these effects are similar but not extrapolable to humans. Our study involved resistance-trained young men with an RT program intervention focused on mechanical tension to generate changes in LBM, considering this as one of the main factors of RT-induced muscle hypertrophy [29, 52, 53]. Also, a 3 min-rest pause between sets and short time under tension was considered, to discourage a dramatic decrease in muscle glycogen. Subsequently, comparison of changes in variables, by one-factor ANOVA, revealed a difference between means in all groups regarding BW and LBM; in fact, there was an increase in LBM (1.3 $[0.5,2.2] \mathrm{kg} ; p<0.05)$ in the NKD group, leading to an increase in BW $(-0.9[-2.3,0.6] \mathrm{kg} ; p<0.05)$. Figure 3 shows significant differences in BW and LBM for NKD group; and FM and VAT for KD group. Likewise, post-hoc analysis showed significant difference in the BW and LBM between KD and NDK groups. These results are in agreement with those obtained by Rauch et al. [54], who compared the effects of a $\mathrm{KD}(5 \% \mathrm{CHO}$, $75 \%$ fat and $20 \%$ protein) with a traditional western diet (55\% $\mathrm{CHO}, 25 \%$ fat and $20 \%$ protein) in men undergoing RT training $(n=26)$, during 11 weeks. These authors also found a decrease in FM in the KD group but, unlike our results, there was an increase in LBM.

The results of the present study are in accordance with the preliminary hypothesis, since analysis of the data showed a significant reduction in FM and VAT in resistance-trained men undergoing a KD while participating in a $\mathrm{RT}$ 
program; however, no changes were seen in LBM in this group. The clinical significance is the reduction in VAT, which could have health benefit because of its inverse correlation to cardiometabolic disease [55, 56]. Regarding to LBM, an adequate carbohydrate intake (non-ketogenic or conventional dietary approach), in conjunction with a caloric surplus and a higher protein intake, might be the most viable option for inducing muscle hypertrophy after RT.

\section{Limitations}

This study has several limitations that should be mentioned. Firstly, this research only included body composition measurements and did not include blood measures. In addition, limited outcome measurements, small number of subjects and intervention time ( 8 weeks) reduce the impact of the study. On the other hand, dietary assessment of appetite suppression by high-fat diet was not performed. So, it is possible to have variations in energy intake even though participants were instructed to follow specific dietary recommendations. Moreover, since KD may affect negatively training volume, we should consider integrating performance measurements or load volume to see changes. In addition, rated perceived exertion might give interesting information about changes during KD adaptation and progression of RT protocol.

\section{Conclusions}

According to our results, we concluded that subjects who underwent $\mathrm{RT}$ during a KD experienced a greater reduction in FM and VAT, when compared to the NKD group. The greater reduction in VAT may have some clinical relevance due to its inverse association to cardio-metabolic risk. Further studies are necessary to evaluate the advantages of this combination (RT and $\mathrm{KD}$ ) in subjects with excess of body FM, with particular attention to the reported significant reduction in VAT, which might be highly beneficial to this population given that LBM is maintained. Indeed, this research showed no significant changes nor effect size on LBM, despite hyperenergetic condition and high protein intake $\left(2.0 \mathrm{~g} \cdot \mathrm{kg}^{-1} \cdot \mathrm{d}^{-1}\right)$ in resistance-trained men of the KD group. Thus, we conclude that low-carbohydrate dietary approaches, such as KD, would not be an optimum strategy for building muscle mass in trained men under the training conditions of this study (mechanical tension-focused RT protocol during 8 weeks).

\section{Abbreviations}

ANOVA: One-way analysis of variance; BMI: Body mass index; BW: Body weight; CG: Control group; DXA: Dual-energy x-ray absorptiometry; ES: Effect size; FM: Fat mass; KB: Ketogenic bodies; KD: Ketogenic diet; LBM: Lean body mass; NKD: Non-ketogenic diet; RT: Resistance training; VAT: Visceral adipose tissue; $n p^{2}$ : Partial eta squared effect size

\section{Acknowledgments}

We are grateful to MSc. Kelly Salgado for her helpful statistics advice.

Funding

Supported by University of Málaga (Campus of International Excellence Andalucía Tech).

\section{Availability of data and materials}

The datasets used and analyzed during the current study are available from the corresponding author on reasonable request.

\section{Authors' contributions}

SV served as study coordinator. SV and IG conceived and designed the experiments. JBP and RR served as lab coordinator and project manager for the study coordination. SV, RR, and JBP assisted in data collection. SV, SE, and IG designed the nutritional protocols. SV oversight nutrition and training. JLP and RBK analyzed the data. JLP, RBK, JBP, and DAB assisted in analysis, and manuscript review. SV, JLP, DAB and JBP wrote the paper. RBK assisted in the statistics advice, discussion analysis, and manuscript preparation. All authors read and approved the final manuscript.

\section{Ethics approval and consent to participate}

Participation in the study was voluntary, with written consent being obtained from each subject before the initiation of data collection. This study was conducted after review and approval by the Ethics Committee of the EADE-University of Wales Trinity Saint David (Málaga, Spain). Committee's reference number: EADECAFYD2017-3.

\section{Consent for publication}

Not applicable.

\section{Competing interests}

The authors declare that they have no competing interests.

\section{Publisher's Note}

Springer Nature remains neutral with regard to jurisdictional claims in published maps and institutional affiliations.

\section{Author details}

${ }^{1}$ EADE-University of Wales Trinity Saint David, Málaga, Spain. ${ }^{2}$ Human Kinetics and Body Composition Laboratory, Faculty of Education Sciences, University of Málaga, Málaga, Spain. ${ }^{3}$ Research Group in Physical Activity, Sports and Health Sciences, Universidad de Córdoba, Montería, Colombia. ${ }^{4}$ Department of Biochemistry and Molecular Biology, Universidad Distrital Francisco José de Caldas, Bogotá, Colombia. ${ }^{5}$ BetterbyScience, Málaga, Spain. ${ }^{6}$ Exercise \& Sport Nutrition Lab, Human Clinical Research Facility, Texas A\&M University, College Station, TX, USA.

Received: 8 March 2018 Accepted: 26 June 2018

Published online: 09 July 2018

\section{References}

1. Evans M, Cogan KE, Egan B. Metabolism of ketone bodies during exercise and training: physiological basis for exogenous supplementation. J Physiol. 2017;595:2857-71.

2. Aragon AA, Schoenfeld BJ, Wildman R, Kleiner S, VanDusseldorp T, Taylor L, Earnest CP, Arciero PJ, Wilborn C, Kalman DS, et al. International society of sports nutrition position stand: diets and body composition. J Int Soc Sports Nutr. 2017;14:16.

3. Paoli A, Grimaldi K, Toniolo L, Canato M, Bianco A, Fratter A. Nutrition and acne: therapeutic potential of ketogenic diets. Skin Pharmacol Physiol. 2012; 25:111-7.

4. Paoli A. Ketogenic diet for obesity: friend or foe? Int J Environ Res Public Health. 2014;11:2092-107.

5. Bueno NB, de Melo IS, de Oliveira SL, da Rocha Ataide T. Very-lowcarbohydrate ketogenic diet $v$. Low-fat diet for long-term weight loss: a meta-analysis of randomised controlled trials. Br J Nutr. 2013;110:1178-87.

6. Gibson AA, Sainsbury A. Strategies to improve adherence to dietary weight loss interventions in research and real-world settings. Behav Sci (Basel). 2017;7:44. 
7. Goday A, Bellido D, Sajoux I, Crujeiras AB, Burguera B, Garcia-Luna PP, Oleaga A, Moreno B, Casanueva FF. Short-term safety, tolerability and efficacy of a very low-calorie-ketogenic diet interventional weight loss program versus hypocaloric diet in patients with type 2 diabetes mellitus. Nutr Diab. 2016;6:e230.

8. Hussain TA, Mathew TC, Dashti AA, Asfar S, Al-Zaid N, Dashti HM. Effect of low-calorie versus low-carbohydrate ketogenic diet in type 2 diabetes. Nutrition. 2012;28:1016-21.

9. Youngson NA, Morris MJ, Ballard B. The mechanisms mediating the antiepileptic effects of the ketogenic diet, and potential opportunities for improvement with metabolism-altering drugs. Seizure. 2017;52:15-9.

10. Martin-McGill KJ, Jenkinson MD, Tudur Smith C, Marson AG. The modified ketogenic diet for adults with refractory epilepsy: an evaluation of a set up service. Seizure. 2017:52:1-6.

11. Martin K, Jackson CF, Levy RG, Cooper PN. Ketogenic diet and other dietary treatments for epilepsy. Cochrane Database Syst Rev. 2016;2:Cd001903.

12. Klement RJ. Beneficial effects of ketogenic diets for cancer patients: a realist review with focus on evidence and confirmation. Med Oncol. 2017;34:132.

13. Oliveira CL, Mattingly S, Schirrmacher R, Sawyer MB, Fine EJ, Prado CM. A nutritional perspective of ketogenic diet in Cancer: a narrative review. J Acad Nutr Diet. 2018:118:668-88.

14. Erickson N, Boscheri A, Linke B, Huebner J. Systematic review: isocaloric ketogenic dietary regimes for cancer patients. Med Oncol. 2017;34:72.

15. Smyl C. Ketogenic diet and Cancer-a perspective. Recent Results Cancer Res. 2016;207:233-40

16. Walczyk T, Wick JY. The ketogenic diet: making a comeback. Consult Pharm. 2017;32:388-96.

17. Chang CK, Borer K, Lin PJ. Low-carbohydrate-high-fat diet: can it help exercise performance? J Hum Kinet. 2017;56:81-92.

18. Burke LM, Ross ML, Garvican-Lewis LA, Welvaert M, Heikura IA, Forbes SG, Mirtschin JG, Cato LE, Strobel N, Sharma AP, Hawley JA. Low carbohydrate, high fat diet impairs exercise economy and negates the performance benefit from intensified training in elite race walkers. J Physiol. 2017;595: 2785-807.

19. Burke LM. Re-examining high-fat diets for sports performance: did we call the 'Nail in the Coffin' too soon? Sports Med. 2015;45(Suppl 1):S33-49.

20. Paoli A, Bianco A, Grimaldi KA. The ketogenic diet and sport: a possible marriage? Exerc Sport Sci Rev. 2015:43:153-62.

21. World Medical Association. Declaration of Helsinki: ethical principles for medical research involving human subjects. J Am Coll Dent. 2014;81:14-8.

22. Helms E, Valdez A, Morgan A: The Muscle and Strength Pyramid: Nutrition. 2015

23. Rozenek R, Ward P, Long S, Garhammer J. Effects of high-calorie supplements on body composition and muscular strength following resistance training. J Sports Med Phys Fitness. 2002;42:340-7.

24. Garthe I, Raastad T, Refsnes PE, Sundgot-Borgen J. Effect of nutritional intervention on body composition and performance in elite athletes. Eur J Sport Sci. 2013;13:295-303.

25. Jager R, Kerksick CM, Campbell BI, Cribb PJ, Wells SD, Skwiat TM, Purpura M, Ziegenfuss TN, Ferrando AA, Arent SM, et al. International Society of Sports Nutrition Position Stand: protein and exercise. J Int Soc Sports Nutr. 2017;14:20.

26. Hall KD, Chen KY, Guo J, Lam YY, Leibel RL, Mayer LE, Reitman ML, Rosenbaum M, Smith SR, Walsh BT, Ravussin E. Energy expenditure and body composition changes after an isocaloric ketogenic diet in overweight and obese men. Am J Clin Nutr. 2016;104:324-33.

27. Wilson JM, Lowery RP, Roberts MD, Sharp MH, Joy JM, Shields KA, Partl J, Volek JS, D'Agostino D. The effects of ketogenic dieting on body composition, strength, power, and hormonal profiles in resistance training males. J Strength Cond Res. 2017. https://doi.org/10.1519/JSC. 0000000000001935

28. Chen JL, Yeh DP, Lee JP, Chen CY, Huang CY, Lee SD, Chen CC, Kuo TB, Kao $\mathrm{CL}$, Kuo $\mathrm{CH}$. Parasympathetic nervous activity mirrors recovery status in weightlifting performance after training. J Strength Cond Res. 2011;25:1546-52.

29. Schoenfeld BJ. The mechanisms of muscle hypertrophy and their application to resistance training. J Strength Cond Res. 2010;24:2857-72.

30. Grgic J, Lazinica B, Mikulic P, Krieger JW, Schoenfeld BJ. The effects of short versus long inter-set rest intervals in resistance training on measures of muscle hypertrophy: a systematic review. Eur J Sport Sci. 2017;17:983-93.

31. Schoenfeld BJ, Pope ZK, Benik FM, Hester GM, Sellers J, Nooner JL, Schnaiter $J A$, Bond-Williams KE, Carter AS, Ross CL, et al. Longer Interset rest periods enhance muscle strength and hypertrophy in resistance-trained men. J Strength Cond Res. 2016;30:1805-12.
32. Proske U, Morgan DL. Muscle damage from eccentric exercise: mechanism, mechanical signs, adaptation and clinical applications. J Physiol. 2001;537:333-45.

33. Schoenfeld BJ, Ogborn D, Krieger JW. Effects of resistance training frequency on measures of muscle hypertrophy: a systematic review and meta-analysis. Sports Med. 2016;46:1689-97.

34. Fleck SJ, Kraemer W. Designing resistance training programs. Champaign: Human Kinetics; 2014

35. Dalton RL, Sowinski RJ, Grubic TJ, Collins PB, Coletta AM, Reyes AG, Sanchez B, Koozehchian M, Jung YP, Rasmussen C, et al. Hematological and hemodynamic responses to acute and short-term Creatine nitrate supplementation. Nutrients. 2017;9(12). https://doi.org/10.3390/nu9121359.

36. Nakagawa S, Cuthill IC. Effect size, confidence interval and statistical significance: a practical guide for biologists. Biol Rev Camb Philos Soc. 2007;82:591-605.

37. Park HM: Comparing group means: t-tests and one-way ANOVA using Stata, SAS, R, and SPSS. 2009

38. Noakes M, Foster PR, Keogh JB, James AP, Mamo JC, Clifton PM. Comparison of isocaloric very low carbohydrate/high saturated fat and high carbohydrate/low saturated fat diets on body composition and cardiovascular risk. Nutr Metab (Lond), 2006:3:7.

39. Brehm BJ, Seeley RJ, Daniels SR, D'Alessio DA. A randomized trial comparing a very low carbohydrate diet and a calorie-restricted low fat diet on body weight and cardiovascular risk factors in healthy women. J Clin Endocrinol Metab. 2003:88:1617-23.

40. Brehm BJ, Spang SE, Lattin BL, Seeley RJ, Daniels SR, D'Alessio DA. The role of energy expenditure in the differential weight loss in obese women on lowfat and low-carbohydrate diets. J Clin Endocrinol Metab. 2005;90:1475-82.

41. Brinkworth GD, Noakes M, Clifton PM, Buckley JD. Effects of a low carbohydrate weight loss diet on exercise capacity and tolerance in obese subjects. Obesity (Silver Spring). 2009;17:1916-23.

42. Johnstone AM, Horgan GW, Murison SD, Bremner DM, Lobley GE. Effects of a high-protein ketogenic diet on hunger, appetite, and weight loss in obese men feeding ad libitum. Am J Clin Nutr. 2008:87:44-55.

43. Ruth MR, Port AM, Shah M, Bourland AC, Istfan NW, Nelson KP, Gokce $\mathrm{N}$, Apovian CM. Consuming a hypocaloric high fat low carbohydrate diet for 12 weeks lowers C-reactive protein, and raises serum adiponectin and high density lipoprotein-cholesterol in obese subjects. Metabolism. 2013;62:1779-87.

44. Wood RJ, Fernandez ML, Sharman MJ, Silvestre R, Greene CM, Zern TL, Shrestha S, Judelson DA, Gomez AL, Kraemer WJ, Volek JS. Effects of a carbohydrate-restricted diet with and without supplemental soluble fiber on plasma low-density lipoprotein cholesterol and other clinical markers of cardiovascular risk. Metabolism. 2007;56:58-67.

45. Gomez-Arbelaez D, Bellido D, Castro Al, Ordonez-Mayan L, Carreira J, Galban C, Martinez-Olmos MA, Crujeiras AB, Sajoux I, Casanueva FF. Body composition changes after very-low-calorie ketogenic diet in obesity evaluated by 3 standardized methods. J Clin Endocrinol Metab. 2017;102:488-98.

46. Volek JS, Sharman MJ, Love DM, Avery NG, Gomez AL, Scheett TP, Kraemer WJ. Body composition and hormonal responses to a carbohydrate-restricted diet. Metabolism. 2002;51:864-70.

47. Upadhyay J, Farr O, Perakakis N, Ghaly W, Mantzoros C. Obesity as a disease. Med Clin N Am. 2018;102:13-33.

48. Ismail I, Keating SE, Baker MK, Johnson NA. A systematic review and metaanalysis of the effect of aerobic vs. resistance exercise training on visceral fat. Obes Rev. 2012;13:68-91.

49. Willis LH, Slentz CA, Bateman LA, Shields AT, Piner LW, Bales CW, Houmard JA, Kraus WE. Effects of aerobic and/or resistance training on body mass and fat mass in overweight or obese adults. J Appl Physiol. 2012;113:1831-7.

50. Roberts MD, Holland AM, Kephart WC, Mobley CB, Mumford PW, Lowery RP, Fox CD, McCloskey AE, Shake JJ, Mesquita P, et al. A putative lowcarbohydrate ketogenic diet elicits mild nutritional ketosis but does not impair the acute or chronic hypertrophic responses to resistance exercise in rodents. J Appl Physiol (1985). 2016;120:1173-85.

51. Holland AM, Kephart WC, Mumford PW, Mobley CB, Lowery RP, Shake JJ, Patel RK, Healy JC, McCullough DJ, Kluess HA, et al. Effects of a ketogenic diet on adipose tissue, liver, and serum biomarkers in sedentary rats and rats that exercised via resisted voluntary wheel running. Am J Physiol Regul Integr Comp Physiol. 2016;311:R337-51.

52. Schoenfeld BJ. Science and development of muscle hypertrophy. Champaign: Human Kinetics; 2016.

53. Schoenfeld BJ. Potential mechanisms for a role of metabolic stress in hypertrophic adaptations to resistance training. Sports Med. 2013:43:179-94. 
54. Rauch JT, Silva JE, Lowery RP, McCleary SA, Shields KA, Ormes JA, Sharp MH, Weiner SI, Georges JI, Volek JS, et al. The effects of ketogenic dieting on skeletal muscle and fat mass. J Int Soc Sports Nutr. 2014;11:P40.

55. Okamura T, Hashimoto Y, Hamaguchi M, Obora A, Kojima T, Fukui M.

Ectopic fat obesity presents the greatest risk for incident type 2 diabetes: a population-based longitudinal study. Int J Obes. 2018. https://doi.org/10. 1038/s41366-018-0076-3.

56. Schousboe JT, Langsetmo L, Schwartz AV, Taylor BC, Vo TN, Kats AM, Barrett-Connor E, Orwoll ES, Marshall LM, Miljkovic I, et al. Comparison of associations of DXA and CT visceral adipose tissue measures with insulin resistance, lipid levels, and inflammatory markers. J Clin Densitom. 2017;20: $256-64$

Ready to submit your research? Choose BMC and benefit from:

- fast, convenient online submission

- thorough peer review by experienced researchers in your field

- rapid publication on acceptance

- support for research data, including large and complex data types

- gold Open Access which fosters wider collaboration and increased citations

- maximum visibility for your research: over $100 \mathrm{M}$ website views per year 